\title{
УТИЛИЗАЦИЯ МЫШЬЯКСОДЕРЖАЩИХ ОТХОДОВ В ЗАКЛАДОЧНОМ МАТЕРИАЛЕ РУДНИКОВ
}

\author{
Б.А. БАЧУРИН \\ Горный институт УрО РАН, г. Пермь
}

\begin{abstract}
Аннотация: Проведены геохимические исследования оценки возможности использования отходов медноперерабатывающих предприятий в качестве компонента закладочной смеси на подземном руднике. Определены содержание и формы нахождения мышьяка в исходных материалах для приготовления закладочных смесей. Исследованы масштабы его выщелачивания из закладочной смеси при контакте с водой в течение 28, 90, 120 и 150 суток. Установлено, что вводимый в состав закладочных смесей мышьяксодержащий кек метастабилен и со временем разлагается, выделяя растворимый мышьяк. В связи с этим, для обеспечения стабильности мышьяксодержащих соединений необходимо вводить в закладочные смеси дополнительные добавки, переводящих мышьяк в более устойчивые формы.

Ключевые слова: медноперерабатывающие предприятия; мышьяксодержащие отходы; закладочные смеси подземных горных выработок; выщелачивание мышьяка; лабораторное моделирование.
\end{abstract}

Проблема обезвреживания и утилизации мышьяксодержащих твердых отходов стоит для многих предприятий цветной металлургии, где в производственном процессе при переработке конвенторных пылей образуется большое количество доменных кеков, содержащих повышенные концентрации соединений мышьяка (от 10 до 85\%) [3]. В настоящее время отходы данного типа передаются специализированным организациям для их складирования в отвалах и хвостохранилищах или захоронения на специальных полигонах, что не исключает поступления мышьяка в окружающую среду. С целью уменьшения негативного влияния на окружающую среду основные усилия направлены на разработку технологий снижения вымывания мышьяка из образующихся твердых отходов с целью сокращения его поступления в гидросферу до экологически приемлемого уровня. Для этого предложено вводить в эти отходы оксид кальция (известь), соли трехвалентного железа, проводить обработку сульфатом железа, сульфидом аммония и др., приводящих к переводу мышьяка в слаборастворимые соединения типа скородита или ферригидрита (мышьяковых гидроксидов трехвалентного железа) [2, 3]. Однако по поводу долговременной стабильности этих соединений существуют достаточно многочисленные и веские опасения. Установлено, что большинство арсенатов и гидроксиларсенатов метастабильны при атмосферных условиях и со временем разлагаются, выделяя растворимый мышьяк [4]. В связи с этим, считается, что для обеспечения стабильности данных форм необходимо постоянно поддерживать подходящие условия хранения [3].

Многочисленные работы у нас в стране и за рубежом были проведены по введению арсенидных отходов в бетон, что приводит, по мнению ряда исследователей, к их связыванию с образованием арсената кальция. Для упрочнения бетонных смесей используются добавки извести, золы, бентонита, растворимого силиката в различных комбинациях. Однако, полученные результаты также оказались неоднозначны. Установлено, что вводимые арсенаты не образуют в бетоне каких-либо соединений, что при определенных условиях может обусловить диффузию мышьяка в окружающую среду. Вымыванию мышьяка из бетона может способствовать также механизм углекислотной коррозии цементного камня [3].

Таким образом, до настоящего времени не выработано единого мнения о механизме стабилизации мышьяка в бетонных смесях. Степень выщелачивания мышьяка из бетонных смесей зависит от состава и форм мышьяксодержащих соединений, что требует исследования этого вопроса в каждом конкретном случае. При этом обращено внимание на то, что с увеличением длительности хранения отходов угроза заражения окружающей среды резко возрастают, т.е. любое складирование или захоронение мышьяксодержащих отходов носит временный характер и представляет потенциальную экологическую опасность. Признано лишь, что мышьяксо- 
держащие бетоны достаточно надежно можно использовать при закладке подземных горных выработок, что позволяет изолировать их от окружающей среды [3].

С целью оценки эффективности данного направления утилизации отходов произведено исследование добавок мышьяксодержащих кеков ОАО «Среднеуральский медеплавильный завод» (СУМЗ) в закладочный материал подземных выработок Гайского ГОКа. По данным электронной микроскопии проба кека СУМЗ состоит из землистых агрегатов горчичножелтого цвета размером 0,1-0,5 мм, по составу отвечающих сульфиду мышьяка, с включениями сульфида свинца (галенит). Последний присутствует как в виде равномерно рассеянных микронных зерен, так и в виде более крупных хорошо ограненных кристаллов. На поверхности некоторых частиц отмечаются новообразованные кристаллы сульфата натрия и цинка (вероятно, чангоит) и в меньшей степени сульфата кальция. Зафиксированы новообразованные кристаллы мышьяка (оксида мышьяка) размером около 0,05 мм.

Определение содержания мышьяка в исследуемых пробах производилось методом спектрометрии с индуктивно связанной плазмой, сопутствующих тяжелых металлов (ТМ) - атомно-абсорбционным методом на спектрометре Квант-АФА-а. Определялось содержание кислоторастворимых и водорастворимых форм данных микроэлементов (МЭ), что позволяет дать оценку максимального содержания их потенциальноподвижных форм и миграционной активности в ионной форме, т.е. может использоваться для оценки возможных масштабов загрязнения водной среды.

Результаты анализа свидетельствуют, что содержание кислоторастворимых форм мышьяка в кеке составляет 19166 мг/кг, водорастворимых форм - 132 мг/кг (0,69\% от доли кислоторастворимых форм), т.е. основная его часть малорастворима в водной среде. Это подтверждается анализом его водной вытяжки, в которой содержание мышьяка составило 166 мг/дм³. Содержание других тяжелых металлов в кеке, особенно их водорастворимых форм, незначительное. Анализ состава водных вытяжек показывает переход в водную фазу кадмия (11,413 мг/дм $\left.{ }^{3}\right)$, свинца $(2,155$ мг/дм³ $)$, никеля $\left(0,364\right.$ мг/дм $\left.{ }^{3}\right)$.

В состав стандартных закладочных смесей, используемых на руднике, входят хвосты обога-

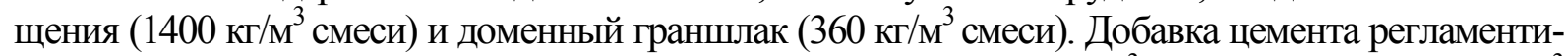

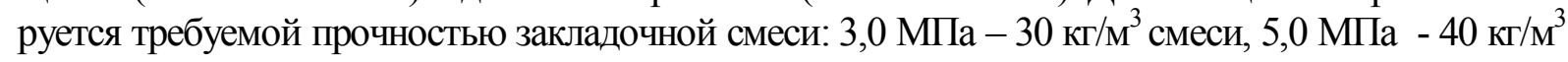
смеси.

Степень загрязнения компонентов закладочной смеси мышьяком и ТМ приведена в таблице № 1 .

Таблица 1

Содержание мышьяка и тяжелых металлов в компонентах закладочной смеси

\begin{tabular}{|c|c|c|c|c|c|c|}
\hline \multirow{2}{*}{$\begin{array}{c}\text { Характеристика } \\
\text { пробы }\end{array}$} & \multicolumn{6}{|c|}{ Содержание, мг/кг } \\
\hline & As & $\mathrm{Cu}$ & $\mathrm{Pb}$ & $\mathrm{Ni}$ & $\mathrm{Zn}$ & $\mathrm{Cd}$ \\
\hline Шлак доменный & $\frac{240,0}{1,66}$ & $\frac{0,003}{\text { не обн. }}$ & не обн. & $\frac{0,006}{\text { не обн. }}$ & $\frac{0,006}{\text { не обн. }}$ & не обн. \\
\hline Хвосты обогащения & $\frac{1477,0}{1,44}$ & $\frac{1,113}{0,0009}$ & $\frac{0,084}{0,003}$ & $\frac{0,017}{0,0003}$ & $\frac{1,255}{0,0004}$ & $\frac{0,004}{0,40}$ \\
\hline Кек СУМЗ & $\frac{19166,0}{132,0}$ & $\frac{1,582}{0,0001}$ & $\frac{0,249}{0,021}$ & $\frac{0,006}{0,0006}$ & $\frac{1,834}{0,003}$ & $\underline{0,179}$ \\
\hline
\end{tabular}

Числитель - кислоторастворимые формы, знаменатель - водорастворимые формы

В проведенных исследованиях закладочные смеси с содержанием цемента 40 и 30 кг $/ \mathrm{M}^{3}$ изготавливались в двух вариантах: без добавления кека (пробы фон 1,2$)$ и с добавлением 1\% кека (пробы СУМЗ 1, СУМЗ 2).

По данным электронной микроскопии и микрозондового анализа (рис. 1) минеральный состав закладочной смеси с добавлением кека характеризуется следующими параметрами: нерудные частицы (цемент, кварц, барит) - 70 \%; пирит, нередко с примесью мышьяка (до 1 мас. \%) - 30 \%; в единичных знаках наблюдаются сульфиды цинка (сфалерит) и свинца 
(галенит), а также землистые агрегаты сложного состава (сульфид свинца, мышьяка, цинка, кадмия, меди, сурьмы и др.), схожие по структуре с частицами кека.

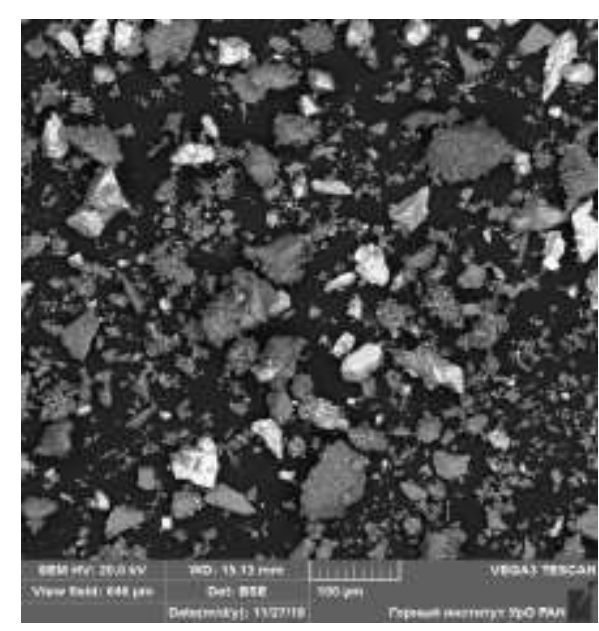

A

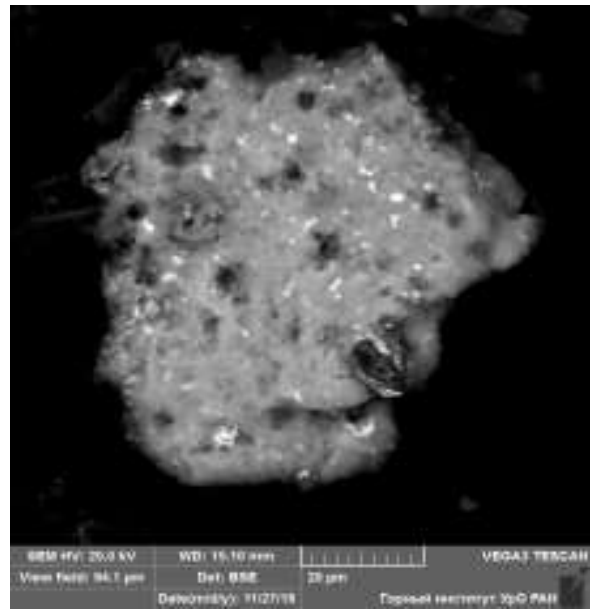

Б

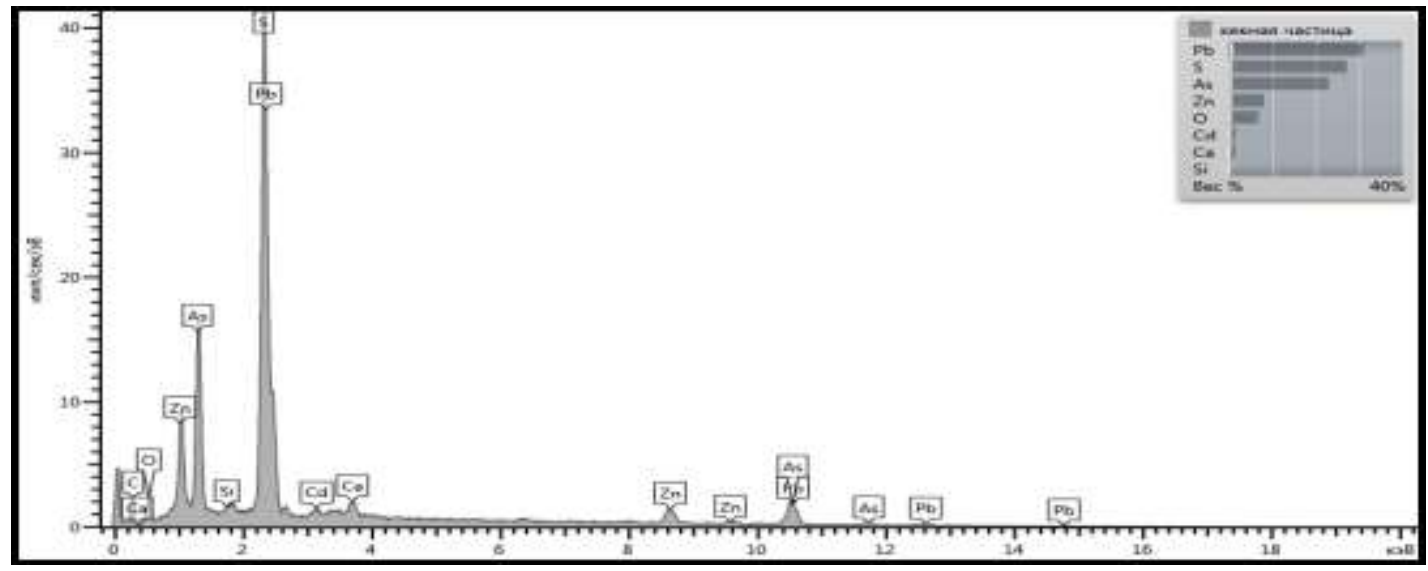

B

Pис. 1. Снимок электронного микроскопа структуры закладочной смеси с добавлением кека (А - общий вид структуры, Б - частица кека) и данные микрозондового анализа ее частиц (B)

Установлено, что вводимые в закладочную смесь частицы кека представляют собой механические взвеси в ее массе, и лишь в незначительном количестве могут образовывать прочносвязанные соединения с другими компонентами.

Результаты исследования содержания мышьяка и ТМ в сформированных закладочных смесях приведено в таблице 2.

Таблица 2

Результаты анализа закладочных смесей

\begin{tabular}{|c|c|c|c|c|c|c|}
\hline \multirow{2}{*}{ Проба } & \multicolumn{6}{|c|}{ Содержание, мг/кг } \\
\hline & As & $\mathrm{Cu}$ & $\mathrm{Pb}$ & $\mathrm{Ni}$ & $\mathrm{Zn}$ & $\mathrm{Cd}$ \\
\hline Фон 1 & 783,0 & $\underline{0,773}$ & $\underline{0,067}$ & $\underline{0,006}$ & $\underline{0,915}$ & $\underline{0,003}$ \\
\hline ФОН 1 & 0,93 & 0,0003 & не обн. & не обн. & не обн. & 0,06 \\
\hline Фон 2 & $\frac{820,0}{0,72}$ & $\frac{0,779}{\text { не обн. }}$ & $\frac{\underline{0,018}}{\text { не обн. }}$ & $\frac{0,008}{\text { не обн. }}$ & $\frac{0,765}{\text { не обн. }}$ & $\frac{0,003}{0,0002}$ \\
\hline СУМЗ 1 & $\frac{3197,0}{16,22}$ & $\frac{0,815}{0,003}$ & $\frac{0,081}{0,0002}$ & $\frac{\underline{0,019}}{\text { не обн. }}$ & $\frac{\underline{0,848}}{\text { не обн. }}$ & $\frac{0,004}{\text { не обн. }}$ \\
\hline СУМЗ 2 & $\frac{4132,0}{31,45}$ & $\frac{0,670}{0,0005}$ & $\frac{0,066}{0,0002}$ & $\frac{0,012}{\text { не обн. }}$ & $\frac{0,735}{\text { не обн. }}$ & $\frac{0,002}{\text { не обн. }}$ \\
\hline
\end{tabular}

Числитель - кислоторастворимые формы, знаменатель - водорастворимые формы 
Основным источником мышьяка в фоновых смесях являются хвосты обогащения: содержание его кислоторастворимых форм - 1477 мг/кг, водорастворимых - 1,44 мг/кг. Добавление в закладочные смеси $1 \%$ кека привело к увеличению содержания в них кислоторастворимых форм мышьяка в 3,9-5,3 раза, водорастворимых форм - в 17,4-33,8 раза (табл. 2). Из других тяжельх металлов отмечено повьшение содержания в составе закладочных смесей свинца (в 1,2-3,7 раза) и никеля (в 1,5-3,2 раза), причем концентрации их водорастворимых форм находится на уровне следов.

Исследование характера выщелачивания мышьяка и ТМ проводилось для монолитных и раздробленных образцов закладочной смеси в статическом режиме (соотношение проба - дистиллированная вода $1: 5)$ при периодическом перемешивании, естественной $\mathrm{pH}$ среды и температуре $25^{\circ} \mathrm{C}$.

Результаты лабораторного моделирования показали, что при контакте воды с закладочной смесью с кеком в течение 28 суток содержание мышьяка в водных вытяжках из монолитных образцов достигло 13,9-28,7 мг/дм³ ступления в водную среду из фоновых проб (рис. 2). Близкие масштабы поступления мышьяка в водную вытяжку отмечены для раздробленных образцов - 13,9- 23,7 мг/дм³.
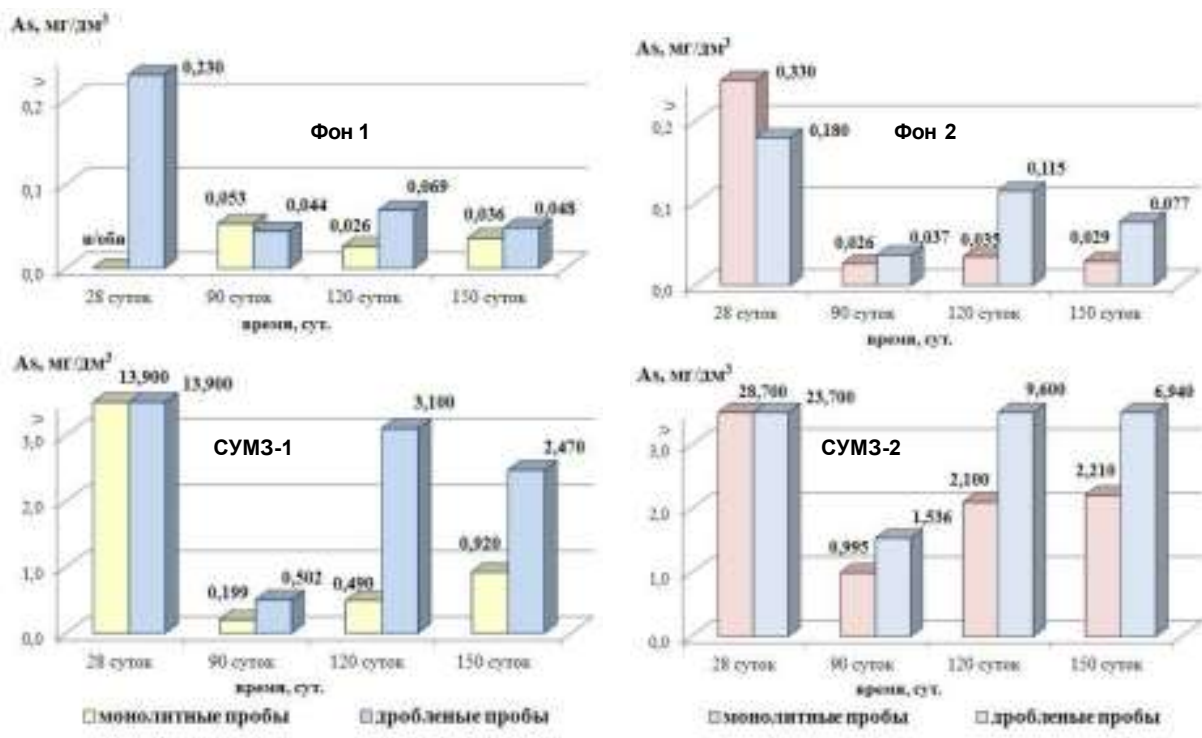

Рис. 2. Характер выщелачивания Аs из закладочных смесей

Увеличение времени контакта воды с закладочной смесью с кеком до 90 суток сопровождается значительным снижением поступления мышьяка в водную фазу: его содержание в водных вытяжках из монолитных образцов колеблется в пределах 0,199-0,995 мг/дм³ ${ }^{3}$ из раздробленных - 0,502-1,536 мг/дм³ ${ }^{3}$ причем максимальные значения характерны для образцов с пониженным содержанием цемента $(30$ кг/м³ $)$. Данные показатели превышают масштабы выщелачивания мышьяка из фоновых образцов в 5-23 раза.

Полученные результаты позволяют предполагать, что на начальном этапе взаимодействия закладочного материала с водой основным источником поступления мышьяка является мелкодисперсная (пылеобразная) фаза, для которой отсутствует прочная связь с минеральной основой закладочной смеси [1]. Растворение данной фазы привело к повышению значений $\mathrm{pH}$ водных вытяжек до 8,75-11,48, при которых фазовый состав цементного камня относительно стабилен [3], что обусловило снижение поступления мышьяка в водную среду (рис. 2).

Вместе с тем, дальнейшее увеличение времени контакта закладочного материала с водой (120-150 сут) приводит к повышению масштабов выщелачивания мышьяка: его содержание в водных вытяжках из монолитных образцов достигает 0,490-2,21 мг/дм³, из раздробленных 2,47-9,60 мг/дм ${ }^{3}$ (максимальные значения характерны для образцов с пониженным содержанием цемента). Это свидетельствует, что длительное взаимодействие закладочной смеси с во- 
дой сопровождается химическим преобразованием мышьяксодержащих соединений кека, приводящим к повышению доли водорастворимых форм, причем более активно данный процесс происходит в раздробленных образцах с пониженным содержанием цемента. Существенную роль играет также формируемая $\mathrm{pH}$ водных растворов $(11,03-11,48)$ : отмечено, что в щелочной среде растворимость сульфидов мышьяка при длительном контакте возрастает [5].

Таким образом, полученные результаты свидетельствуют, что закладочный материал с добавлением мышьяксодержащих кеков не является стабильным и разрушается при длительном взаимодействии с водной средой. Этому способствует то, что вводимые закладочную смесь частицы кека в большинстве своем не образуют каких-либо соединений, а представляют механические взвеси в образующейся массе.

Как показывает анализ опыта работ [3], снижение масштабов выщелачивания мышьяка из бетонных смесей может быть достигнуто введением в их состав различных добавок (соли трехвалентного железа, сульфид аммония, фосфаты и др.), переводящих мышьяк в относительно стабильные соединения (скородит, ферригидрит). Возможно также введение в состав смесей различных стабилизирующих добавок (нефтеуглеродные и другие органические жидкости), основным назначением которых является гидроизоляция мышьяксодержащих частиц.

Для оценки эффективности данных мероприятий необходимо проведение дополнительных исследований по разработке наиболее оптимальных рецептур закладочных смесей.

\title{
БИБЛИОГРАФИЧЕСКИЙ СПИСОК
}

1. Бачурин Б.А. Геохимические аспекты утилизации мышьяксодержащих отходов // Проблемы минералогии, петрографии и металлогении: науч. чтения памяти П.Н. Чирвинского / ПГНИУ [и др.]. - Пермь, 2019. - Вып. 22. - С. 363-368.

2. Исабаев С.М., Кузгибекова Х.М., Жинова Е.В., Зиканова Т.А. Исследование поведения соединений мышьяка в различных средах // Международный научно-исследовательский журнал. - 2013. - № 8-2 (15). - С. 22-24.

3. Копылов Н.И., Каминский Ю.Д. Мышьяк. - Новосибирск: Сибирское университетское изд-во, 2004. - 363 с.: ил.

4. Твидвелл Л.Дж., Плессас К.О., Комба П.Г., Данке Д.Р. Удаление мышьяка из сточных вод и стабилизация мышьяксодержащих твердых отходов // Цветные металлы. - 1996. - № 9. - С. 27-31.

5. Smedley P.L., Kinniburgh D.C. A review of the source, behaviour and distribution of arsenic in natural waters // Applied Geochemistry. - 2002. - V .17. - P. 517-568.

\section{МЕХАНИКА ГОРНЫХ ПОРОД}

УДК 622.83

DOI: $10.7242 /$ echo.2019.2.5

\section{О ВОЗМОЖНОСТИ ИЗВЛЕЧЕНИЯ КАРНАЛЛИТОВОЙ РУДЫ В ПОТЕНЦИАЛЬНО ОПАСНЫХ ЗОНАХ}

\author{
Е.А. ГУБАНОВА \\ Горный институт УрО РАН, г. Пермь.
}

\begin{abstract}
Аннотация: Рассмотрены варианты ведения очистных работ в окрестности охранного околоскважинного целика за счет создания зон смягчения путем закладки очистных камер одного из рабочих пластов. Математическое моделирование процессов деформирования и разрушения водозащитной толщи (ВЗТ) проведено в двухмерной упругопластической постановке для условий плоского деформированного состояния (ПДС) методом конечных элементов. С использованием критериев Кулона-Мора и предельных растягивающих напряжений проведен анализ эффективности создания зон смягчения в динамике нарастания оседаний земной поверхности. Выполнен анализ потенциальной возможности формирования в подработанном массиве трещин субвертикальной ориентации как основных при формировании водопроводящих каналов по разрезу ВЗТ. Представлены результаты геомеханических расчетов при использовании дополнительных мер охраны на примере Верхнекамского месторождения калийно-магниевых солей (ВКМКС).

Ключевые слова: математическое моделирование; водозащитная толща; субвертикальная нарушенность; зона смягчения.
\end{abstract}

